\title{
An Experimental Study on Mechanical and Fracture Behavior of Phosphoric Iron
}

\author{
A. K. Vishnoi ${ }^{a^{*}}$, B.K. Mishra ${ }^{a}$, S. Prakash ${ }^{\text {b }}$ \\ ${ }^{a}$ Department of Mechanical and Industrial Engineering, IIT Roorkee, India \\ ${ }^{\mathrm{b}}$ Department of Metallurgical and Materials Engineering, IIT Roorkee, India \\ *Corresponding Author: amitvishnoi.iitr@gmail.com
}

\begin{abstract}
Phosphoric iron of two different phosphorus content, namely $\mathrm{P}_{1}$ (Fe-0.30P-0.226C), $\mathrm{P}_{2}$ (Fe$0.11 P-.028 C)$ were first prepared by ingot casting route. The ingot were soaked and forged at $1150^{\circ} \mathrm{C}$. The microstructures of the phosphoric iron and its relevant mechanical properties such as hardness and tensile properties have been characterized. $J$-R curves of the material have been determined at room temperature. Fracture behaviour under tearing load has been studied through fracture toughness tests on phosphoric iron using Compact Tension (CT) specimens of Width $(W)=50 \mathrm{~mm}$ and thickness $(B)=12.5 \mathrm{~mm}$. $\mathrm{J}$-R curves were obtained from specimens precracked to $a / W=0.5$.The single specimen unloading compliance method have been used for generating $J$-R curves.
\end{abstract}

\section{INTRODUCTION}

Simple fracture is the separation of body into two pieces in response to the applied stresses. The applied stresses may be tensile, compressive, shear or torsional or a combination of them. Fracture of engineering structures is one of the most dreadful failures of the structural materials as it involves human lives and the structures itself. The problem of fracture has been greatly increased due to the amplified use of complex structures. As a result, extensive investigation were initiated in many countries and the work revealed that pre-existing flaws or high stress concentration region present in structure could initiate the crack and the propagation of such crack lead to the final fracture of the component or structure.

The corrosion behaviour of iron containing high phosphorous or phosphoric irons is an unexplored area of corrosion science and engineering. Recent research work on Delhi Iron Pillar [1-4], a good example of high phosphorus containing iron, has revealed some of its corrosion resistance properties. Research on Delhi Iron Pillar (DIP) provided the current impetus to 
understand the corrosion behaviour of Fe-P alloy. The average composition of phosphorous in the DIP is about $0.25 \mathrm{wt} \%$, while that of carbon is $0.15 \%$ [2]. Irons, containing phosphorous contents of this order have been subjected to research by Balasubrahmaniyam et al [5]. His group has studied the corrosion properties of phosphoric iron manufactured by the ingot route [5].

Phosphorus increases the yield and ultimate tensile strengths with a corresponding reduction in ductility as measured by elongation and reduction in area, to a point where brittle failure occurs. This loss of ductility occurs during prolonged exposure of steel in the temperature range of 250$600^{\circ} \mathrm{C}$ [6-9]. This condition is frequently encountered in tempering of steel. Hence it is called temper embrittlement. Phosphorous increases the ductile to brittle transition temperature of steel. It causes brittleness in steel during cold working [10-12].

In present work, an attempt has been made to determine the mechanical properties and fracture behaviour of phosphoric iron for two different phosphorus content, namely $\mathrm{P}_{1}(\mathrm{Fe}-0.30 \mathrm{P}-$ $0.226 \mathrm{C}), \mathrm{P}_{2}(\mathrm{Fe}-0.11 \mathrm{P}-.028 \mathrm{C})$.

\section{EXPERIMENTAL PROCEDURE}

\subsection{Materials}

The materials used for the present investigation are the two compositions of phosphoric iron. The phosphoric irons were produced by ingot casting. For obtaining $1 \mathrm{~kg}$ of phosphoric iron containing $0.1 \% \mathrm{P}$, we require $0.001 \mathrm{~kg}$ P. For obtaining $50 \mathrm{~kg}$ phosphoric iron with $0.1 \% \mathrm{P}$, we require $0.050 \mathrm{~kg} \mathrm{P}=50 \mathrm{gm} \mathrm{P}$. As $0.176 \mathrm{~kg} \mathrm{P}$ is present in $1 \mathrm{~kg} \mathrm{Fe}-\mathrm{P}$ alloy, $0.050 \mathrm{~kg} \mathrm{P}$ is present in $0.050 / 0.176=284 \mathrm{gm} \mathrm{Fe}-\mathrm{P}=0.284 \mathrm{~kg}$ of Ferro-phosphorous alloy. Similarly, for obtaining $0.3 \% \mathrm{P}$, we require $0.003 \mathrm{~kg}$ P. For obtaining $50 \mathrm{~kg}$ phosphoric iron with $0.3 \% \mathrm{P}$, we require $0.150 \mathrm{~kg} \mathrm{P}=150 \mathrm{gm} \mathrm{P}$. As $0.176 \mathrm{~kg} \mathrm{P}$ is present in $1 \mathrm{~kg} \mathrm{Fe}-\mathrm{P}$ alloy, $0.150 \mathrm{~kg} \mathrm{P}$ is present in $0.150 / 0.176=852$ gm Fe-P $=0.852 \mathrm{~kg}$ of ferro-phosphorous alloy.

\subsubsection{Melting and casting}

Utilizing a high frequency induction-melting furnace of $300 \mathrm{Kg}$ capacity, $100 \mathrm{Kg}$ of soft iron was first melted. To the molten iron, initially $25 \mathrm{Kg}$ of steel scrap was added. During melting, slag covered the melt. Some of this slag was removed from the top of the melt. After proper melting of soft iron and steel scrap, approximately one third of the meet was transferred to a ladle, which was in the form of bucket of about 1.5 feet height. As per the calculations, the required amount of Fe-P mother alloy was added during taping of the melt into the ladle. Finally, the melt from the ladle was poured from the top side into a square mould, $50 \mathrm{~cm}$ height and $100 \mathrm{~cm}$ square cross-section.

\subsubsection{Reheating and soaking}

A high temperature furnace was used for reheating the ingots and soaking at desired temperature $\left(1150^{\circ} \mathrm{C}\right)$. The ingots were placed in the furnace and the furnace was then heated. It took about 5 
hours to reach the temperature $\left(1150^{\circ} \mathrm{C}\right)$. Ingots of different compositions were soaked at $1150^{\circ} \mathrm{C}$, successively for two hours of soaking. The logic for selecting $1150^{\circ} \mathrm{C}$ is as follows. Heat- treating at this temperature is expected to produces a duplex microstructure consisting of austenite in the grain boundaries of ferrite.

\subsubsection{Forging}

Each ingot was forged at $1150^{\circ} \mathrm{C}$ in to $25 \mathrm{~mm}$ thick plates. In successive stages of forging, each reduced plate was reheated again to $1150^{\circ} \mathrm{C}$ for a short time for the further reduction of dimension. For example, when the thickness was reduced down to around $40 \mathrm{~mm}$, the reduced plate is again reheated at $1150^{\circ} \mathrm{C}$ for 15 minutes in the furnace for reheating purpose because longer time of reheating may lead grain growth. The $40 \mathrm{~mm}$ thick plate was again forged to obtain $25 \mathrm{~mm}$ thickness.

Table 1: Average composition of phosphoric iron after soaking and forging

\begin{tabular}{|l|l|l|l|l|l|l|l|l|l|l|}
\hline $\begin{array}{l}\text { Sam } \\
\text { Ple }\end{array}$ & $\mathrm{C}$ & $\mathrm{P}$ & $\mathrm{Si}$ & $\mathrm{Mn}$ & $\mathrm{S}$ & $\mathrm{Ni}$ & $\mathrm{Cr}$ & $\mathrm{Mo}$ & $\mathrm{V}$ & $\mathrm{Cu}$ \\
\hline $\mathrm{P}_{1}$ & 0.226 & 0.30 & 0.159 & 0.223 & 0.009 & 0.026 & 0.145 & 0.005 & 0.001 & 0.031 \\
\hline $\mathrm{P}_{2}$ & 0.028 & 0.11 & 0.029 & 0.046 & 0.017 & 0.026 & 0.044 & 0.004 & 0.003 & 0.033 \\
\hline
\end{tabular}

\subsection{Hardness Evaluation}

Hardness was evaluated with the help of a Vickers Hardness Tester using a load of $10 \mathrm{kgf}$. The specimen surfaces used for hardness studies were polished prior to hardness examination. At least five indentations were taken to estimate the average value of hardness of the phosphoric iron under investigation.

\subsection{Tensile Testing}

Round specimens of diameter $4 \mathrm{~mm}$ and gauge length $16 \mathrm{~mm}$ were fabricated for tensile tests following the ASTM standard E8 [13] from the as received block. The nominal dimensions of the tensile specimens are shown in Fig. 1. Specimens were fabricated for evaluating tensile properties. All tests were carried out at a cross-head velocity of $0.003 \mathrm{~mm} / \mathrm{sec}$. The tests were conducted at room temperature. The tensile data were analyzed to estimate the yield strength (YS), ultimate tensile strength (UTS), uniform elongation (eu), total elongation (et) and reduction in area.

Standard cylindrical tensile specimen according to ASTM E-8 used for tensile testing. Length of reduced section (A) is $20 \mathrm{~mm}$, distance between shoulders (B) is $28 \mathrm{~mm}$, diameter of reduced section $\left(D_{1}\right)$ is $4 \mathrm{~mm}$, grip diameter $\left(D_{2}\right)$ is $8 \mathrm{~mm}$, and radius of curvature $(R)$ is $4 \mathrm{~mm}$. 


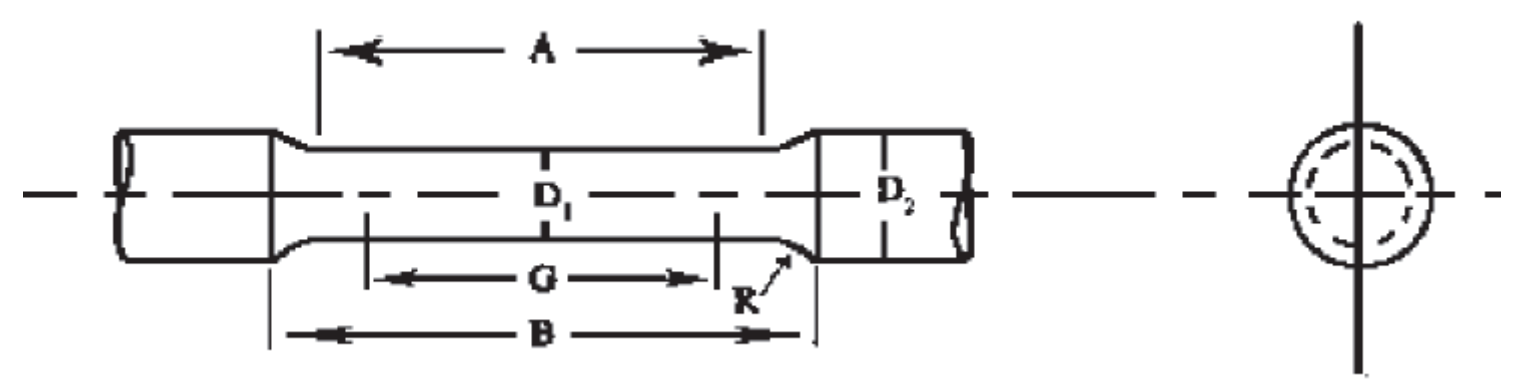

Figure 1: Nominal dimensions of the tensile specimens

\subsection{J-Integral Test}

\subsubsection{Specimen preparation}

The fracture toughness tests in this investigation were planned on compact tension specimens in L-T orientation. Considering the available form of the material, standard CT specimens were machined following the guidelines of ASTM E 399-90 [14], in orientation, LT of the crack plane. Typical configuration of a specimen is shown in Fig. 2 the designed dimensions of the specimens were; thickness $(B)=12.5 \mathrm{~mm}$, width $(\mathrm{W})=50 \mathrm{~mm}$ and machine notch length $\left(\mathrm{a}_{\mathrm{N}}\right)=$ $10 \mathrm{~mm}$.

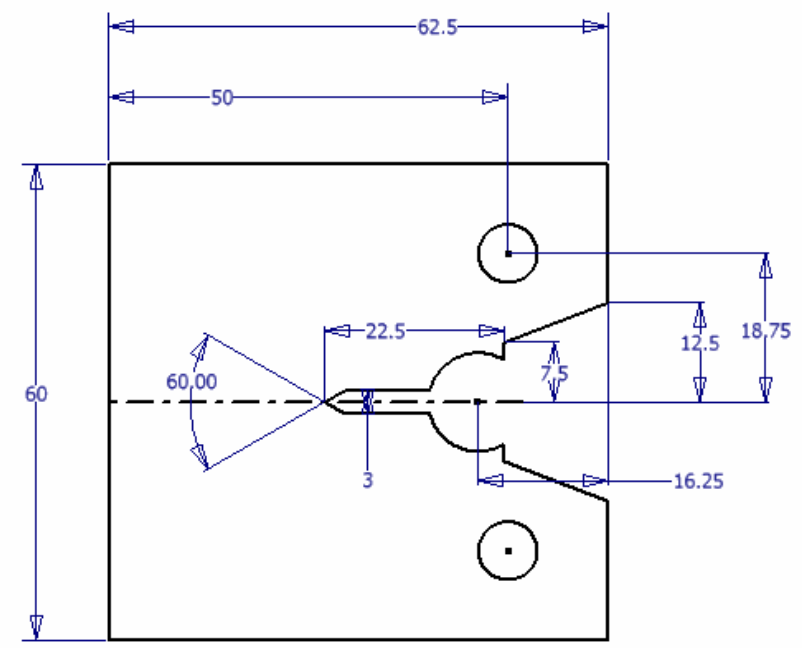

Figure 2: Dimensions of CT specimen 


\subsubsection{Fatigue pre-cracking}

Testing was done at room temperature at cyclic stress frequency of $10 \mathrm{~Hz}$. In the test fatigue crack was initiated and propagated under tension sinusoidal loading for a stress ratio $\mathrm{R}=0.1$, pre-cracking load calculated by the following formula

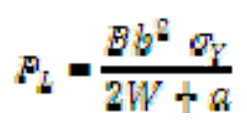

Where $\mathrm{B}=$ thickness of $\mathrm{CT}$ specimen, $\sigma_{Y}$ is yield strength, a initial crack length, $\mathrm{b}$ uncrack ligament, $\mathrm{W}=$ width of $\mathrm{CT}$ specimen.

For pre-cracking load condition is $0.4 \mathrm{P}_{\mathrm{L}}, \mathrm{P}_{\max }, \mathrm{P}_{\min }$ are calculated for pre-cracking of specimen

$$
\begin{gathered}
\mathrm{P}_{\max }=0.4 \mathrm{P}_{\mathrm{L}} \\
\mathrm{P}_{\min }=0.1 \mathrm{P}_{\max }(\text { stress ratio } 0.1)
\end{gathered}
$$

\subsubsection{Fracture toughness testing}

In the single specimen J-integral tests unloading should not exceed more than $50 \%$ of the current load value and hence design and control of the test procedure is important. Some initial trial experiments indicated that a specific actuator displacement control for the selected iron could lead to the desired test procedure. This control consisted of loading a specimen to a level of $0.3 \mathrm{~mm}$, unloading through $0.15 \mathrm{~mm}$, reloading through $0.15 \mathrm{~mm}$ and then repeating the sequence till an appreciable load drop was noticed on the load displacement plot. The displacement cycles were carried out using an actuator rate of $0.003 \mathrm{~mm} \mathrm{~s}^{-1}$. The tests were controlled through a computer attached to the machine. The actuator displacement, load and the load line displacement (LLD), were recorded continuously throughout the test at a frequency of $2 \mathrm{~Hz}$. The magnitude of LLD was monitored by a crack opening displacement (COD) gauge of $10 \mathrm{~mm}$ gauge length attached to the specimen. A minimum of approximately 35 data points of load-LLD was collected from the unloading part of the loading sequence for crack length calculations.

\subsubsection{Generation of J-R curve:}

Calculation of $\mathbf{J}$ : The magnitude of $\mathrm{J}$ is the sum of its elastic and plastic component denoted by $\mathrm{J}_{\mathrm{el}}$ and $\mathrm{J}_{\mathrm{pl}}$. The elastic component of $\mathrm{J}$ was calculated using the equation

$$
\begin{gathered}
\mathrm{J}=\mathrm{J}_{\mathrm{el}}+\mathrm{J}_{\mathrm{pl}} \\
\mathrm{J}_{\mathrm{el}}=\mathrm{K}_{\mathrm{i}}^{2}\left(1-v^{2}\right) / \mathrm{E}+\mathrm{J}_{\mathrm{pl}}
\end{gathered}
$$

where $\mathrm{K}_{\mathrm{i}}$ the elastic stress intensity parameter is evaluated using the expression given below [15] 


$$
\begin{aligned}
& K_{Q}=\frac{\mathrm{B}}{\sqrt{\mathrm{EE}_{W}} \sqrt{W}} f\left(\frac{\mathrm{B}_{1}}{W}\right)
\end{aligned}
$$

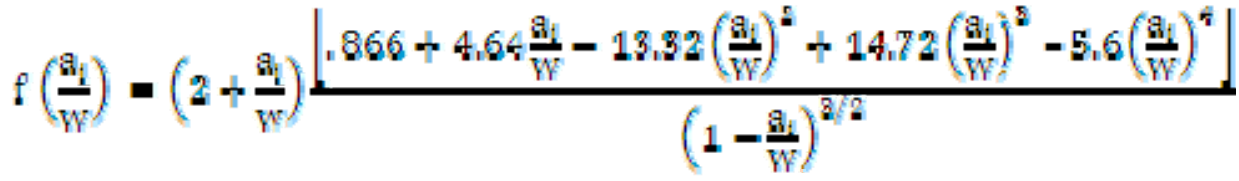

The magnitude $\mathrm{J}_{\mathrm{pl}}$ of was calculated by considering only load vs. plastic load line displacement. In order to obtain the latter, the elastic part of displacement at different loads was first calculated from the slope of the initial load-LLD diagram. A simple subtraction of the elastic component from the total displacement yielded the plastic part of LLD. The area under the load vs. plastic LLD data from the start of the test to the load of interest was calculated to obtain the magnitude of .This was done by using the expression [16]

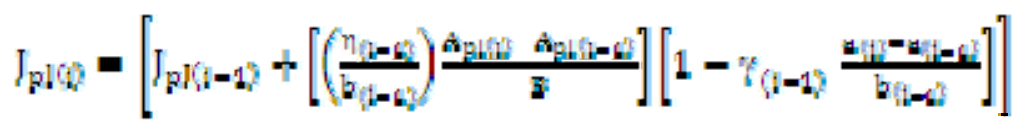

where ,

$$
\begin{gathered}
\eta_{(i-1)}=2.0+\frac{0.220 b_{i-1}}{w} \\
\gamma_{(i-1)}=1.0+0.76 b_{i j-1 /} / w
\end{gathered}
$$

The quantity $A_{\mathrm{g} z(t)}-A_{\mathrm{g} z(t-1)}$ is the increment of plastic area under the force versus plastic loadline displacement record between lines of constant displacement at points i-1 and i. The quantity $\mathrm{J}_{\mathrm{gl} i \mathrm{i}}$ represents the total crack growth corrected plastic $\mathrm{J}$ at point $\mathrm{i}$ and is obtained in two steps by first incrementing the existing $I_{\mathrm{pl}\{\mathrm{i}-1}$ and then by modifying the total accumulated result to account for the crack growth increment .Accurate evaluation of $J_{p l}$ from the above relationship requires small and uniform crack growth increments consistent with the suggested elastic compliance spacing. The quantity $A_{\mathrm{y} i}$ can be calculated from the following equation.

$$
A_{B V}=A_{B l(i-1)}+\frac{1}{2}\left[\left(B_{1}+P_{(i-1)}\right)\left(V_{B V}-V_{B l(i-1)}\right)\right]
$$

where,

$\mathrm{V}_{\mathrm{pl}(\mathrm{i})}=$ plastic part of the load-line displacement, $\mathrm{V}_{(\mathrm{i})}-\left(\mathrm{P}_{(\mathrm{i})} \mathrm{C}_{\mathrm{LL}(\mathrm{i})}\right.$, and

$\mathrm{C}_{\mathrm{LL}(\mathrm{i})}=$ experimental compliance, $(\Delta \mathrm{V} / \Delta \mathrm{P})$, corresponding to current crack size

\subsubsection{Calculation of crack size:}

The inverse of the slope yielded the compliance $\left(\mathrm{C}_{\mathrm{i}}\right)$ of the specimen corresponding to the load from which the unloading has been carried out. The obtained $C_{i}$-values were corrected for the 
specimen rotation using the following expression to get the corrected compliance $\left(C_{c i}\right)$ of the specimen at that particular load [17].

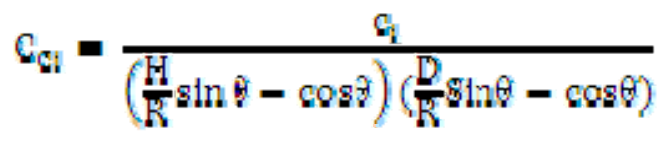

$\mathrm{H}=$ initial half-span of the load points (centre of pin holes)

$\mathrm{R}=$ radius of rotation of the crack centre line, $(\mathrm{W}+\mathrm{a}) / 2$ where $\mathrm{a}$ is the updated crack length.

$\mathrm{D}=$ one half of the initial distance between the displacement measurement points

$\theta=$ angle of rotation of a rigid body element about the unbroken midsection line, or

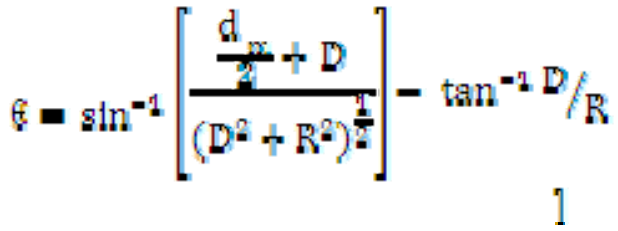

$d_{m}=$ Total measured load-line displacement

The crack length $\left(\mathrm{a}_{\mathrm{i}}\right)$ at this point of interest was next estimated using the expression suggested by Hudak et. al. [18]

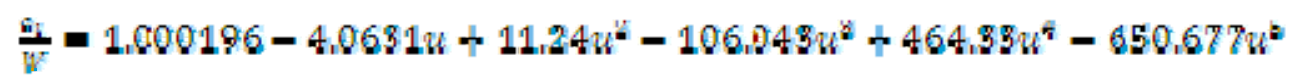

where,

$$
u=\frac{1}{\left(E E C_{g k}\right)^{1 / 2}+1}
$$

$\mathrm{W}=$ width of the specimen

$\mathrm{B}=$ total thickness of the specimen

The obtained values of $\mathrm{J}$ and the corresponding crack extension $\Delta \mathrm{a}$ were plotted to get the $\mathrm{J}-\Delta \mathrm{a}$ curves of the material in various test conditions.

\subsection{Fractography}

The end of the ductile crack extension during loading of the specimens, subjected to J-integral test, was marked by post fatigue cracking, and then the specimens were loaded to fracture. The fractured surfaces were ultrasonically cleaned and examined using a scanning electron microscope. This was done to record the interesting features of stable crack extension.

\section{Results and Discussions}

Hardness was evaluated with the help of a Vickers Hardness Tester using a load of $10 \mathrm{kgf}$ as shown in Table: 2. The five indentations were taken to estimate the average value of hardness of the steel under investigation. 
Table 2: Hardness value of specimens

\begin{tabular}{|c|c|}
\hline SAMPLE & Hardness HV \\
\hline $\mathbf{P}_{11}$ & $\mathbf{2 0 2}$ \\
\hline $\mathbf{P}_{12}$ & 190 \\
\hline $\mathbf{P}_{13}$ & $\mathbf{2 1 0}$ \\
\hline $\mathbf{P}_{21}$ & 179 \\
\hline $\mathbf{P}_{22}$ & 170 \\
\hline $\mathbf{P}_{23}$ & 165 \\
\hline
\end{tabular}

\subsection{Tensile Test}

The tensile tests were conducted at room temperature. The stress strain plot for $\mathrm{P}_{11}$ and $\mathrm{P}_{12}$ is shown in Fig. 3 while for $\mathrm{P}_{21}$ and $\mathrm{P}_{22}$ is shown in Fig. 4 along with the tensile properties in Table 3.

Table 3: Tensile Properties of Phosphoric Iron $P_{1}$

\begin{tabular}{|c|c|c|}
\hline Specimen & Yield stress, (MPa) & Ultimate tensile stress (Mpa) \\
\hline $\mathbf{P}_{11}$ & 434.7 & 664 \\
\hline $\mathbf{P}_{12}$ & 344.2 & 573 \\
\hline $\mathbf{P}_{13}$ & 480 & 610 \\
\hline
\end{tabular}
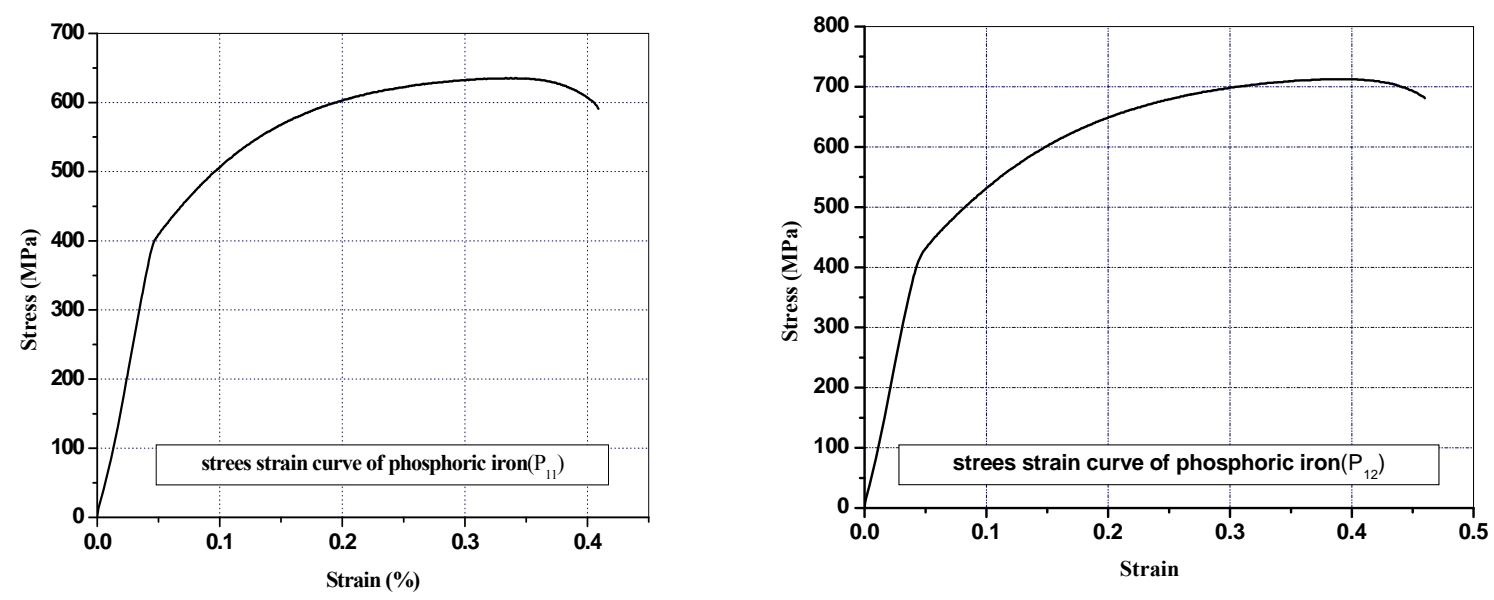

Figure 3: Stress strain diagram for specimen $\mathrm{P}_{11}$ and $\mathrm{P}_{12}$ 

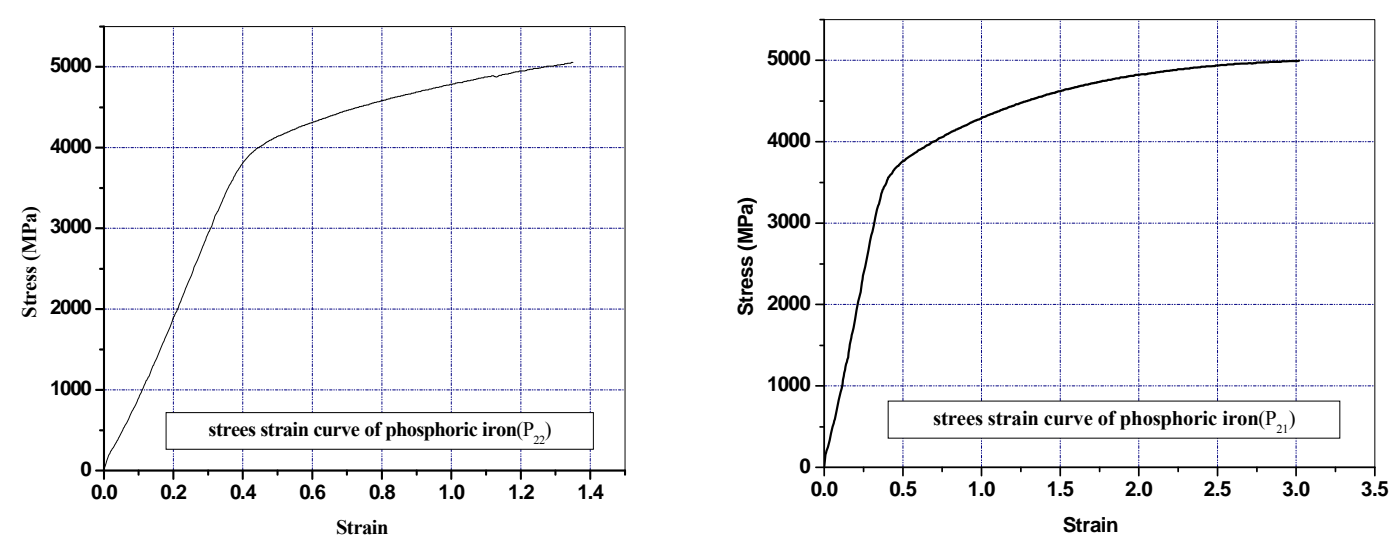

Figure 4: stress strain diagram for specimen $\mathrm{P}_{21}$ and $\mathrm{P}_{22}$

\subsection{J-integral Fracture Toughness}

Pre-crack load was calculated as below:

$$
\begin{aligned}
& F_{11 \text { max }}=\frac{8 \operatorname{lab}^{2} g k}{2 W^{n a}}=16.9 \mathrm{KN} \\
& \mathrm{P}_{12 \mathrm{max}}=11.59 \mathrm{KN} \\
& f\left(\frac{Q_{i}}{W}\right)=\left(2+\frac{Q_{i}}{W}\right) \frac{\left[.866+4.64 \frac{Q_{t}}{W^{2}}-1.32\left(\frac{Q_{i}}{W}\right)^{2}+14.72\left(\frac{Q_{i}}{W^{2}}\right)^{2}-5.6\left(\frac{Q_{t}}{W^{2}}\right)^{4}\right]}{\left(1-\frac{Q_{t}}{W^{2}}\right)^{\frac{2}{2}}}=8.34
\end{aligned}
$$

Then an exclusion line is drawn parallel to the construction line intersecting the abscissa at 0.15 $\mathrm{mm}$. A second exclusion line is drawn parallel to the construction line intersecting the abscissa at $1.5 \mathrm{~mm}$. A $\mathrm{J}-\Delta \mathrm{a}$ data points that fall inside the area enclosed by these two parallel lines are plotted.

In order to fit the power law equation for $\mathrm{J}-\mathrm{R}$ curve, the experimental points of $\mathrm{J}$ vs. $\Delta \mathrm{a}$ lying between two exclusion lines were considered. The exclusion lines were constructed parallel to the experimental blunting line at $\Delta \mathrm{a}$-offset values of 0.15 and $1.5 \mathrm{~mm}$ following the ASTM standard E-1820 [37].

A line parallel to the experimental blunting line at $\Delta \mathrm{a}=0.2 \mathrm{~mm}$ was next constructed. The intersection of this offset line with the fitted J-R curve was considered as the critical value of $\mathrm{J}$, i.e. $\mathrm{J}_{\mathrm{Q}}$. 
A $0.2 \mathrm{~mm}$ offset blunting line was drawn. The intersection of the blunting line with the power law curve at an offset of $0.2 \mathrm{~mm}$ was considered as $\mathrm{J}_{\mathrm{Q}}$. $\mathrm{J}_{\mathrm{i}}$ was determined at intersection of blunting line with power law curve as shown in Figure 5-8.

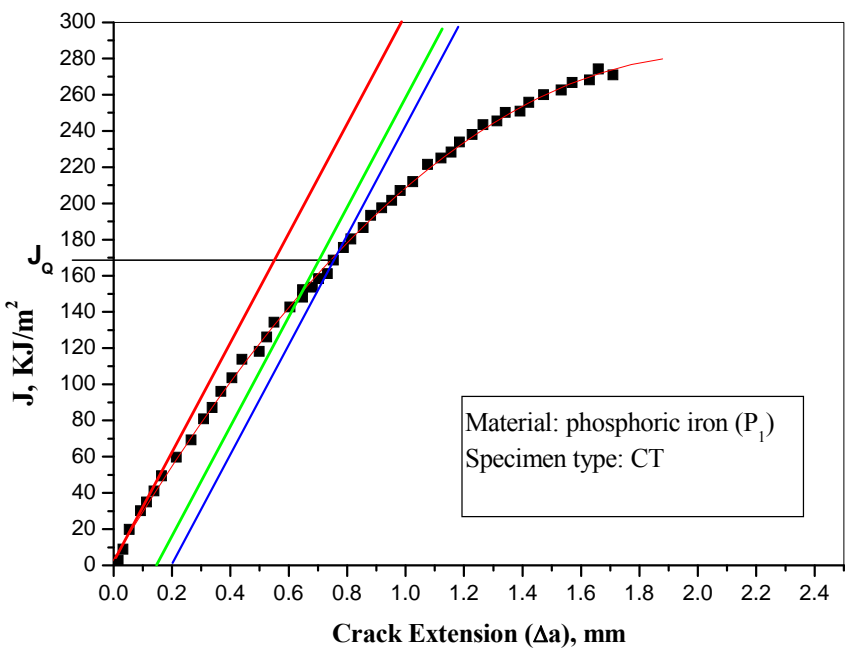

Figure 5 : J-R for curve specimen

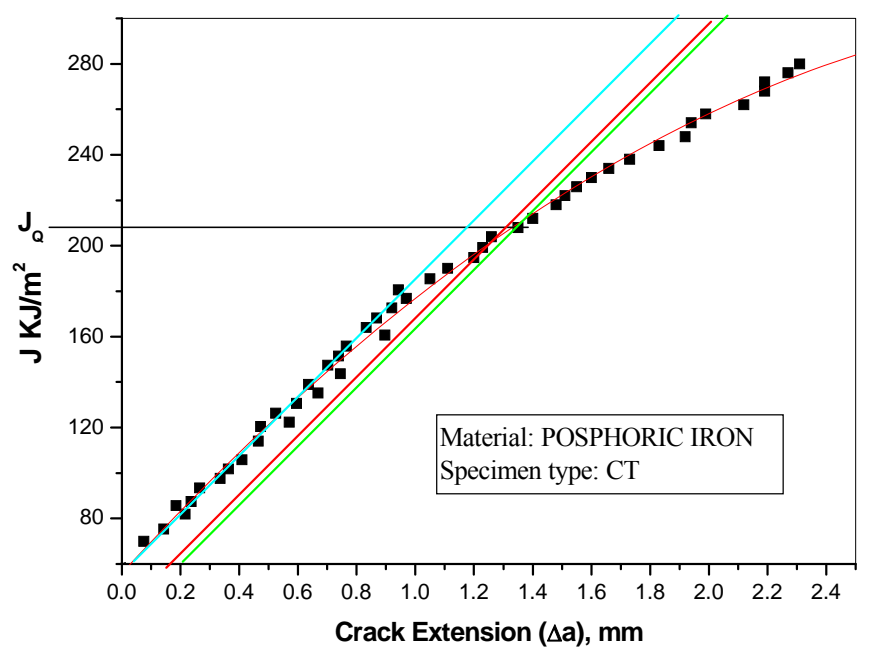

Figure 6: J-R for curve specimen $\mathrm{P}_{12}$ 


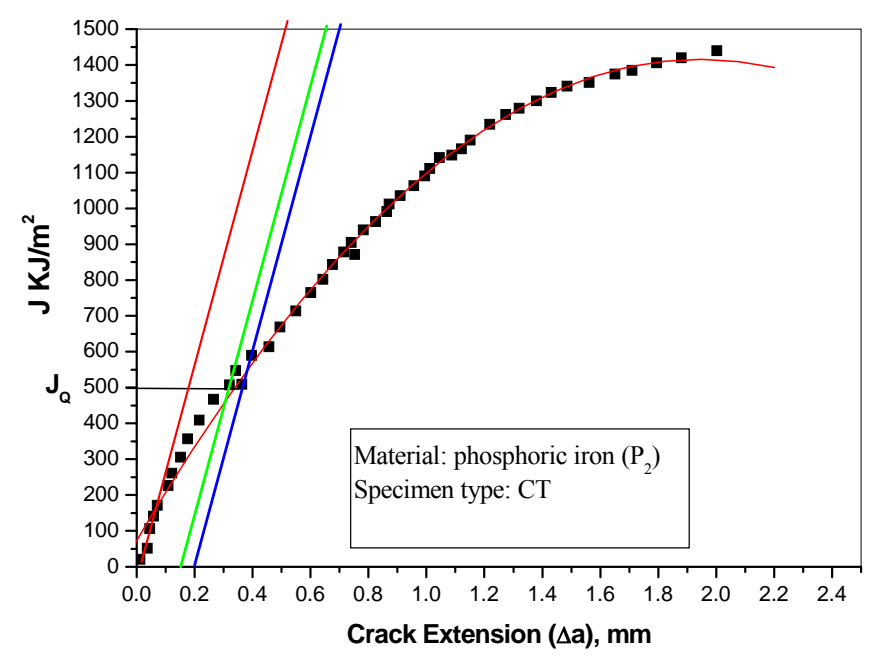

Figure 7: J-R for curve specimen $\mathrm{P}_{21}$

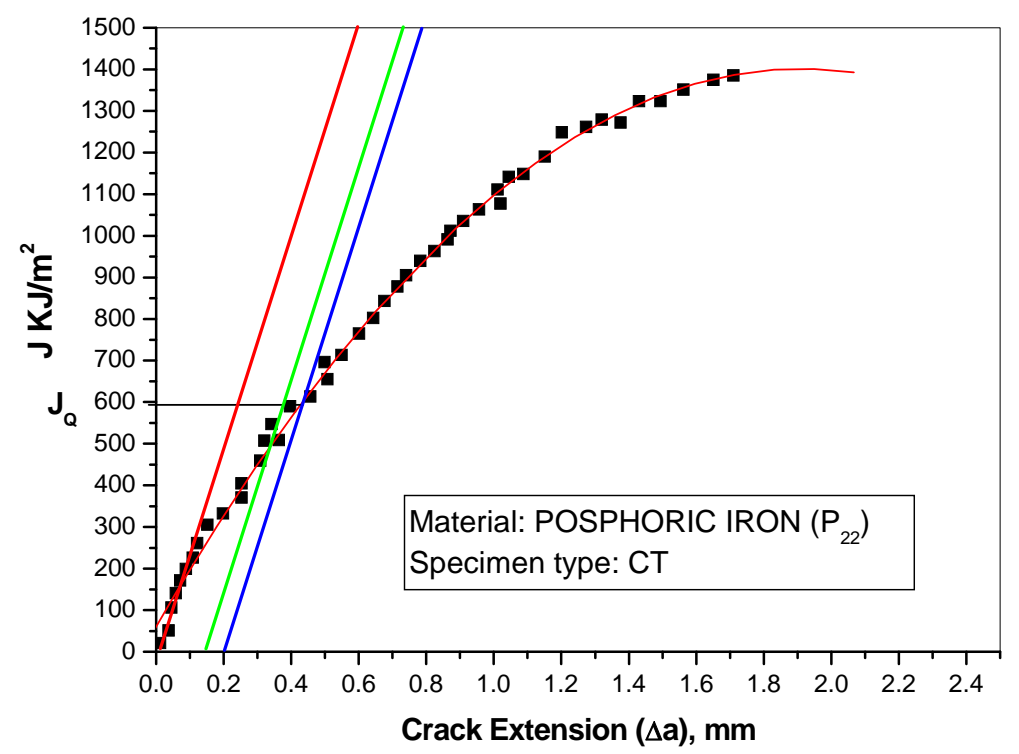

Figure 8: $\mathrm{J}-\mathrm{R}$ for curve specimen $\mathrm{P}_{22}$

Table 4 : Thickness validity criteria of the specimens for fracture toughness test:

\begin{tabular}{|l|l|l|l|l|}
\hline Specimen & $\sigma_{0} \mathrm{MPa}$ & $\mathbf{J}_{\mathbf{Q ~ K J} / \mathbf{m}}{ }^{2}$ & $\mathrm{~B}$ & $10\left(\mathrm{~J}_{\mathbf{Q}} / \boldsymbol{\sigma}_{\mathbf{0}}\right)$ \\
\hline $\mathbf{P}_{11}$ & 549 & 170 & 12.5 & 3.0 \\
\hline$P_{12}$ & 458 & 210 & 12.5 & 4.5 \\
\hline$P_{21}$ & 376.4 & 500 & 12.5 & 13.3 \\
\hline$P_{22}$ & 371.1 & 590 & 12.5 & 15.8 \\
\hline
\end{tabular}

$\sigma_{\mathrm{o}}=$ flow stress, $\mathrm{J}_{\mathrm{Q}}=$ critical value of $\mathrm{J}$

$\mathrm{B}=$ specimen thickness, and $10\left(\mathrm{~J}_{\mathrm{Q}} / \sigma_{\mathrm{o}}\right)=$ thickness criterion. 


\subsection{J Integral Fracture Toughness of Phosphoric Iron}

The estimated average J-integral fracture toughness values of the phosphoric iron at room temperature are $170 \mathrm{KJ} / \mathrm{m}^{2}$ (Table 4) for specimens $P_{11}$. And for specimen $P_{12}$ is $210 \mathrm{KJ} / \mathrm{m}^{2}$. J integral fracture toughness for $\mathrm{P}_{21}$ is $500 \mathrm{KJ} / \mathrm{m}^{2} . \mathrm{P}_{21}$ and $\mathrm{P}_{22}$ specimen is fail in thickness criteria.

\subsection{Fractography}

The fractured surfaces were ultrasonically cleaned and examined using a scanning electron microscope. For $\mathrm{P}_{1}$ specimen:

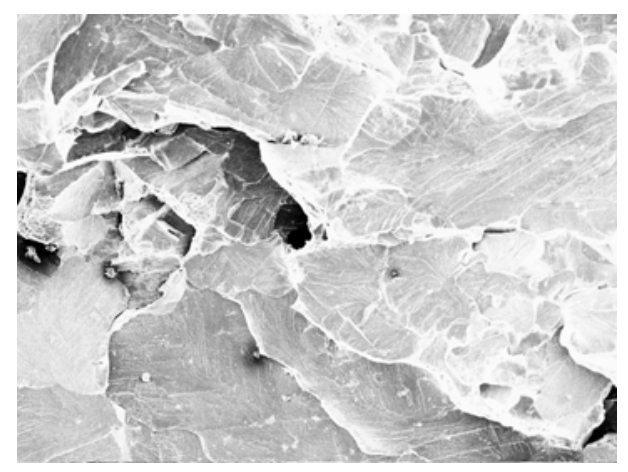

(a)

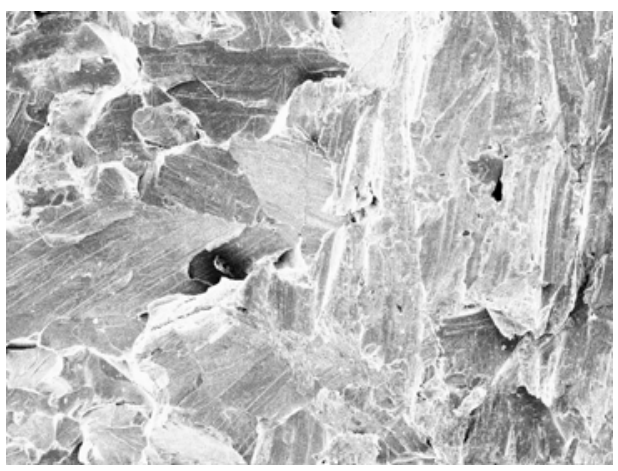

(b)

Figure 9 : SEM micrograph of fracture surface of specimen $\mathrm{P}_{1}$ obtained at different magnification

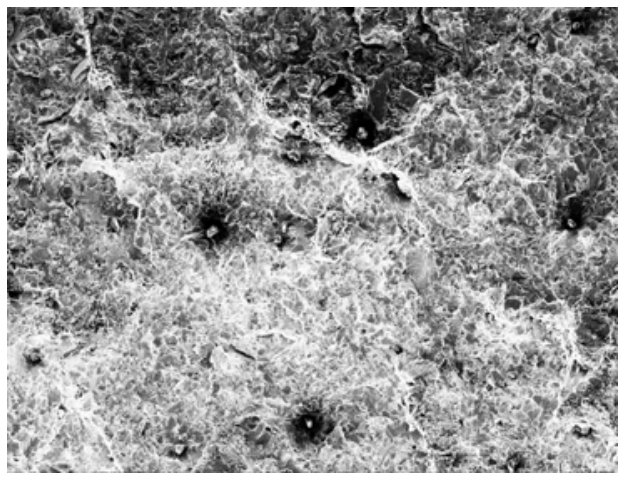

(a)

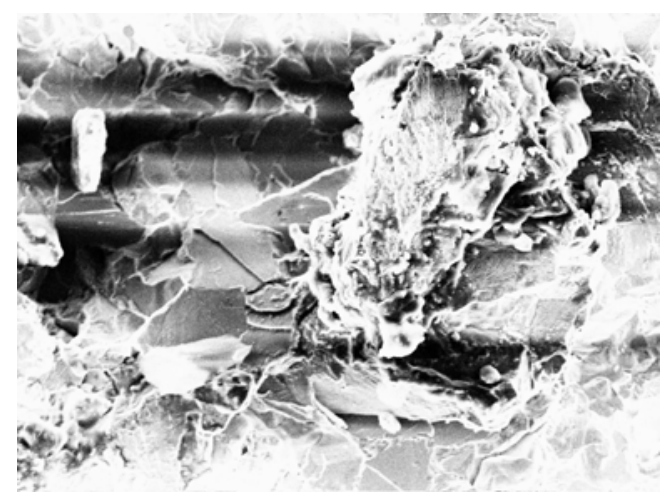

(b)

Figure 10: SEM micrograph of fracture surface of specimen $\mathrm{P}_{2}$ obtained at different magnification

The fracture surface of specimen decohesive $\mathrm{P}_{1}$ (Figure 9) rupture (which is also called as intergranular fracture) and brittle trans-granular cleavage fracture. Fracture surface of specimen as 
received $\mathrm{P}_{2}$ revealed equiaxed and elliptical dimple (Figure 10) under SEM which show the ductile behaviour.

\section{CONCLUSION}

The phosphoric iron $\mathrm{P}_{1}(\mathrm{Fe}-0.30 \mathrm{P}-0.226 \mathrm{C}), \mathrm{P}_{2}$ (Fe-0.11P-.028C) were prepared by ingot casting route. The ingots were soaked and forged at $1150{ }^{\circ} \mathrm{C}$. The microstructures were subjected to metallographic examination. Mechanical properties and $\mathrm{J}_{\mathrm{IC}}$ were evaluated and compare with mild steel.

Hardness of as received phosphoric iron increased with increasing phosphorus content, indicative of solid solution strengthening effect of phosphorus in phosphoric irons. Effect of phosphorus in phosphoric iron was confirmed from the observed increasing trend of yield stress and ultimate tensile stress with increasing phosphorus content. A decreasing trend of ductility (both percentage elongation and percentage reduction in area at failure) with increasing phosphorus content was also noted. The $\mathrm{J}_{\mathrm{Q}}$ fracture toughness value of CT of $\mathrm{P}_{1}$ specimen prepared from the phosphoric iron satisfy the criteria suggested in ASTM E- 1820 standard. Fracture toughness for specimen $\mathrm{P}_{1}(\mathrm{Fe}-0.30 \mathrm{P}-0.226 \mathrm{C})$ is $170 \mathrm{KJ} / \mathrm{m}^{2}$ and $210 \mathrm{KJ} / \mathrm{m}^{2}$. It is comparable to mild steel $\left(179 \mathrm{KJ} / \mathrm{m}^{2}\right)$. Fracture surface of specimen as received $\mathrm{P}_{2}$ revealed equiaxed and elliptical dimple under SEM, while that of $\mathrm{P}_{1}$ (Fe-0.30P-0.226C) revealed both decohesive rupture and transgranular cleavage fracture. Phosphoric iron is a new class of engineering materials with good fracture toughness and corrosion resistance properties.

\section{REFERENCES}

1. R. Balasubrahmaniam, "On the Corrosion Resistance of the Delhi Iron Pillar". Corrosion Science, 42(2000), Pp: 2103-2129.

2. G Wranglen, “The Rustless Iron Pillar at Delhi”. Corrosion Science, 10(1970),Pp: 761-770

3. R. balasubrahmaniam and AV Kumar." Characterization of the DIP Rust by XRD, FTIR and Mossbauer Spectroscopy”. Corrosion science, 42(2000), Pp: 2085-2101

4. Gadadhar Sahoo and R. Balasubramaniam. "Corrosion of Phosphoric Irons in Acidic Enviornments” Journal of ASTM International, 5(2008), Pp: 1-7

5. R Balasubrahmaniam and A V Kumar, "On the Origin of High P Content in Ancient Indian Irons.” International Journal of Metals, materials and processes, 14(2002), Pp: 1-14.

6. J M Capus and G Meyer, "The Mechanical Properties of Some Tempered Alloy Martensites". Journal of the iron and steel institute, 196(1960), Pp: 149-158.

7. C.L. Briant and S.K.Banerji, "Phosphorus Induced $350{ }^{\circ} \mathrm{C}$ Embrittlement in an UltrahighStrength Steel”, Metallurgical Transaction A: Physical Metallurgy and Materials Scince, 10 A (1979) 123-126.

8. R.M. Horn and R.O. Ritchie, "mechanism of tempered martensite embrittlement in low alloy steel," Metallurgical Transaction A: Physical Metallurgy And Materials Scince, 9 A (1978) 1039-1053 
9. J.P. materkowski and G. Krauss. "Tempered Martensite Embrittlement In SAE 4340 Steel". Metallurgical Transaction A : Physical Metallurgy And Materials Scince 10A (1979) 16431651

10. C.J. Mcmahon Jr., American Socity Of Testing Materials, ASTM STP 407 (1968) 127.

11. Y.Q. Weng and C.J.Mchmanhon, "Interaction Of Phosphorus, Carbon, Manganese, And Chromium In Intergranular Embrittlement Of Iron", Materials Science Technology, 3 (1987),207-216

12. M. Goodway and R.M. Fisher, "Phosphorus In Low Carbon Iron: Its Beneficial Properties", Historical Metallurgy, 22 (1988) 21-23

13. ASTM E 8M-94a, "Test Methods for Tension Testing of Metallic Materials (Metric)", Annual Book of ASTM Standards, Vol.03.01, p.81-100, ASTM, Philadelphia, PA, (1994)

14. ASTM E399, "Standard Test Method for Plan Strain Fracture Toughness of Metallic Materials", Annual Book of ASTM Standards, Section 3, (1996)

15. H. Roy, S. Sivaprasad, S. Tarafder, K.K. Ray, "Monotonic vis-à-vis cyclic fracture behavior of AISI 304LN stainless steel”, Engineering Fracture Mechanics (2009)

16. ASTM E1820-08a Standard test method for Measurement of Fracture Toughness, Annual Book of ASTM Standards, Vol.03.01, p.1-34, ASTM, Philadelphia, PA, 2008

17. ASTM E 647-93, Standard Test Method for Measurement of Fatigue Crack Growth Rates, Annual Book of ASTM Standards, 1994, Vol.03.01, pp.569-596, ASTM, Philadelphia, PA.

18. Pickering F.B., [1977], "The structure and properties of banite in steels, in transformation and hardenability in Steels", Climax Molybdenum Company of Michigan, Ann Arbor, MI, p 109-13 